ИСКУССТВОВЕДЕНИЕ

DOI: $10.17805 /$ trudy.2016.2.3

\title{
ПРОБЛЕМЫ РЕЖИССУРЫ ТЕАТРА
}

\author{
B. А. Юркин \\ (Московский гуманитарный университет)
}

Аннотация: В статье анализируются цели и задачи режиссуры театра, роль режиссера в процессе работы коллектива над созданием спектакля.

Ключевые слова: режиссер; театр; спектакль; художественный образ; творчество; творческий работник

\section{ISSUES OF STAGE DIRECTING}

\author{
V. A. Yurkin \\ (Moscow University for the Humanities)
}

\begin{abstract}
The article looks at the aims and objectives of stage directing, as well as the director's role in creating a theatrical performance alongside with the troupe.

Keywords: stage director; theatre; performance; artistic image; creative work; creative professional
\end{abstract}

Режиссер (франц. regisseur, от лат. rego - управляю) - это творческий работник тетра, осуществляющий постановку драматического (пьеса) или музыкального (опера, оперетта) произведения на сцене. В современном театре такой режиссер называется режиссером-постановщиком или просто постановщиком спектакля. Режиссер возглавляет весь процесс работы коллектива над созданием спектакля. Осуществляя определенную интерпретацию пьесы (оперы, оперетты), он добивается творческого раскрытия замысла драматурга (композитора), определяет идейную направленность спектакля и ту общую задачу, ради которой ставится пьеса (Бейлис, Иванов, 2009). Стремясь к наиболее полному раскрытию содержания литературного или музыкального произведения через систему сценических образов, режиссер объединяет в едином замысле творческие усилия актеров, художника-декоратора, композитора и других участников постановки. Он является организатором всех работ, связанных с созданием спектакля. Важнейшая часть деятельности режиссера - работа с актерами, направленная на развитие дарования исполнителей применительно к каждой роли. 
Режиссер работает, репетирует с актером, вызывает в актере творческий процесс, вдохновляет актера, поддерживает и непрерывно направляет его к определенной цели в соответствии с общим идейно-художественным замыслом спектакля. Режиссер формирует (воспитывает) актера.

Режиссер согласовывает результат творчества каждого актера с результатом творчества остальных исполнителей для создания гармонически целостного единства спектакля; он является организатором всех работ, связанных с созданием спектакля. Режиссером создается театральное произведение.

Для того чтобы быть хорошим режиссером, нужно быть прирожденным актером. Режиссер должен владеть сложным искусством композиции. От режиссера требуется понимание и ясное, точное определение сверхзадачи и сквозного действия каждой роли. Режиссеру необходимо уметь работать с актерами. Режиссер пользуется выразительными средствами (темпоритм, мизансцена, свет, музыка), выделяет, акцентирует выразительными средствами любой момент сценического действия, распределяет сцены и эпизоды по их значимости в отношении сверхзадачи спектакля, делит сцены и эпизоды на главные, второстепенные и третьестепенные. Режиссер должен уметь думать и сам должен так строить свою работу, чтобы она возбуждала у зрителей мысли, нужные современности. Задача режиссера - выразить и донести до зрителя идею спектакля через творчество актера, используя при этом все компоненты спектакля (декорации, музыку и т. д.). Задача режиссера - формирование художественного образа спектакля, эмоционально выражающего его главную мысль - идею, сверхзадачу (К. С. Станиславский).

Режиссерский разбор спектакля. Первый этап в постановке будущего спектакля - предварительная работа режиссера над пьесой. Режиссер должен не только глубоко проникнуть в драматическое произведение, но и представить себе рисунок - композицию будущей постановки.Перед ним - две серьезные задачи: 1) Всестороннее и глубокое изучение пьесы (на основе этого изучения возникает режиссерский замысел постановки); 2) Составление режиссерского плана работы над спектаклем.

Всестороннее и глубокое изучение пьесы - это определение ее темы и идеи. Тема всегда отвечает на вопрос: «О чем пьеса?» В центре любой истории стоит герой или группа героев. Героем может быть только существо с человеческой психологией. При определении темы необходимо указать героя (про кого пьеса), то, к чему стремится герой и что он делает для достижения цели. Идея представляет собой общечеловеческую истину, которая, как правило, не дает достаточной пищи для фантазии. Идея в чем-то схожа с моралью, которую мы выносим после прочтения пьесы.

Для того, чтобы всесторонне изучить пьесу, необходимо:

а) Как можно глубже вникнуть в содержание произведения: установить 
события и конфликты, из которых складывается сюжет пьесы;

б) Представить себе во всем качественном разнообразии человеческих индивидуальностей те образы героев пьесы, которые стоят в центре событий и являются причиной основного драматургического конфликта;

в) Найти сквозное действие, которое служит проводником идеи «сверхзадачи» в пьесе. Сквозное действие осуществляет в пьесе становление идеи, выявляет ее развитие, то есть борьбу со всем, что противостоит ей по ходу сюжета, и, наконец, завершается торжеством идеи.

Одним из самых важных моментов в этот период является умение режиссера читать, перечитывать, «вчитываться» в пьесу для самого себя. Начинать режиссерскую работу, основываясь только на первом впечатлении от художественного произведения, неверно. Прочтя пьесу, спросите себя, все ли вам в ней понятно, хорошо ли запомнился сюжет пьесы? Точное знание сюжета, умение четко представить себе его во всех деталях - первое требование, которое должен предъявить к себе режиссер. Режиссер должен совершенно четко представить себе образ - характер каждого действующего лица: вплоть до рядового участника массовой сцены, «влезть в шкуру» каждого персонажа. Только тогда режиссер поймет, какие черты характера заставляют героев пьесы действовать так, а не иначе. Представьте себе подробно прошлое действующих лиц, пофантазируйте о том, что они бы делали после закрытия занавеса. Все эти упражнения на фантазию позволят с разных сторон определить поступки действующих лиц, дополнить их характеристики.

Режиссер должен знать фактическую, конкретную обстановку, в которой развертывается действие, как всей пьесы, так и каждого акта и сцены в отдельности.

К первой задаче режиссера в период его самостоятельной работы над пьесой относится также определение главных и второстепенных событий, из которых состоит каркас сюжета пьесы. Обычно каждое событие совпадает с интересами и желаниями одних действующих лиц и противоречит интересам и желаниям других. Первые делают из события выводы и решения одного порядка, вторые - другого. Из этих противоречий возникает драматический конфликт. Каждое событие начинается столкновением и кончается разрешением этого столкновения, составляя, таким образом, как бы отдельные звенья пьесы.

Важно определить не только смысл каждого события в пьесе, но и его действенное выражение. Чтобы логика событий пьесы стала в спектакле наиболее яркой, действенной, предельно выражающей идею, режиссер еще в период анализа драматического произведения должен определитьсквозное действие пьесы. Сквозное действие как на вертел нанизывает все важнейшие события пьесы. Сквозное действие помогает режиссеру отыскать в пьесе те отдельные в каждом событии действия, через которые возникает 
идея пьесы; затем те главные действия, в которых развертывается борьба «за» и «против» идеи произведения; и наконец, то действие, которое приводит к торжеству, к победе идеи.

Таким образом, сквозное действие теснейшим образом связано с идеей - сверхзадачей пьесы.

Необходимо проделать всю эту большую работу, и тогда идея пьесы станет ясной и можно будет увидеть, что из первоначальных замыслов годится для ее сценического воплощения, а что представляет плод случайной, пусть яркой, но необязательной ассоциации.

Режиссерский замысел и постановочный план. На основе всестороннего изучения и глубокого разбора драматического произведения у режиссера уже в первый период его работы над пьесой рождается замысел постановки, возникают контуры будущего спектакля. В процессе замысла отдельные компоненты спектакля не всегда возникают в логической последовательности. У каждого художника творческое воображение работает по-своему. Может быть так, что режиссер еще изучает пьесу, а у него уже возникает зрительное представление центральной картины, и он отмечает, какие режиссерские акценты надо будет расставить и кого назначить на главные и второстепенные роли в этой картине, чтобы она явилась кульминационной точкой спектакля.

Режиссерский замысел - это то, без чего не может обойтись ни один спектакль. Прежде чем что-то воплощать, надо хорошо понять идею произведения, иметь свой подход к пьесе. Признавая всю важность и значение режиссерского замысла, надо твердо помнить, что наличие одного замысла не решает успеха дела. Глубокий, интересный режиссерский замысел - это только начальная стадия работы над пьесой.

Необходим известный последовательный план дальнейшей работы режиссера над пьесой. Через этот план, а он называется постановочный план, создается спектакль. Постановочный план включает в себя организацию режиссером всех работ по будущему спектаклю.

В постановочный план режиссера входит: выбор художника, который будет осуществлять оформление спектакля, а также композитора и хореографа, если таковы необходимы по сюжету пьесы и замыслу режиссера. В постановочный план входит составление режиссером календарного плана всей работы над спектаклем. Начиная от первой репетиции и кончая днем выпуска спектакля.

Режиссеру важно прочесть пьесу не столько «эффективно», сколько верно. Верно прочесть пьесу - означает выявить, что в произведении и в характерах действующих лиц главное, что второстепенное; безошибочно знать подтекст (то есть скрытые за текстом мысли), чувствовать нарастание действия в пьесе и ритм ее. Актеры при верной читке легко запоминают 
содержание и сквозное действие пьесы, а также особенности художественного стиля автора. Ни в коем случае режиссер не должен стремиться, читая, «играть» за действующих лиц. Когда пьеса прочитана, режиссер обязан ответить на все возникшие у актеров вопросы. Затем под свежим впечатлением можно приступать к обсуждению пьесы.

Обсуждение пьесы должно определить:

1. идейное содержание пьесы - ее сверхзадачу;

2. события и предлагаемые обстоятельства, то есть, в каких условиях, в какое время, эпоху, при каких внешних обстоятельствах происходит действие пьесы;

3. сквозное, то есть главное, действие пьесы;

4. действия и задачи каждой роли в каждом событии пьесы; взаимоотношения персонажей и их отношение к событиям пьесы и к окружающей их среде;

5. главные черты характеров действующих лиц.

К самому процессу чтения пьесы по ролям режиссер должен предъявлять совершенно точное требование. Оно заключается в том, чтобы актер с первых дней работы над ролью не читал ее, а говорил - действовал текстом роли, то есть, чтобы у исполнителей весь процесс работы за столом над пьесой с каждым днем все больше превращался в разговор - действие текстом пьесы. Необходимо убедить их в том, что работа над ролью начинается не с заучивания текста, а с большого предварительного изучения той среды, в которую автор помещает героев своего произведения.

Когда исполнители хорошо поработали над содержанием пьесы, представили себе, в какую эпоху, в какой среде, при каких обстоятельствах развивается ее действие, составили биографию своих образов, необходимо вместе с ними определить сквозное действие пьесы. Это один из важнейших моментов в работе режиссера с актерами. Ведь известно, что идея пьесы на сцене должна выявляться в действии, в борьбе взаимоотношений героев, в столкновении событий пьесы. В этой борьбе идея пьесы находит свое становление, развитие, торжество.

Задача режиссера - найти такие действия, такую логику событий в пьесе, которая наиболее глубоко и сценически выразительно воплощала бы ее идею. Эту цепь важнейших действий в пьесе мы называем сквозным действием, которое должно с наибольшей силой выявить идею - сверхзадачу пьесы и спектакля, то есть то, ради чего автор написал произведение, а театр поставил спектакль.

Линия действия, поведения героя пьесы, рассматриваемая в непосредственном взаимодействии с окружающей его средой, а на сцене - в первую очередь с партнерами его по пьесе, является тем сквозным действием, которое в процессе работы актера над ролью будет постепенно наполняться 
богатством внутренней психической жизни человека, составляющего сущность данного образа.

Следующий этап совместного обсуждения пьесы - это разбор характеров действующих лиц. Под понятием «характер» или «образ» действующего лица мы условимся понимать:

1. Отношение действующего лица к совершающимся событиям. Его мироощущение, миросозерцание;

2. Его действия и поступки в пьесе;

3. Круг отношений данного действующего лица ко всем остальным персонажем пьесы; из этих отношений всегда станут, ясны индивидуальные черты характера данного образа - действующего лица.

Кроме того, пользуясь всем материалом пьесы, актер должен суметь представить себе прошлое каждого образа, или как мы говорим, создать биографию действующего лица.

Что значит характер в жизни и поведении любого человека? Прежде всего, это то, как человек видит мир вокруг себя (одного все раздражает, другого радует, третьего печалит, один по темпераменту меланхолик, другой флегматик). Что думает о себе каждый человек в жизни, как он сам видит (один самоуверен, другой, наоборот, постоянно сомневается в себе, третий скромен). Что человек решил в жизни совершить, какова его жизненная задача. У одного личные интересы: удобства, деньги, машина, дача; другой мечтает встать в ряды ученых и всю жизнь посвятить науке; третий хочет быть художником, артистом, музыкантом... Образ слагается не только из внутренних черт характера, он проявляется и во внешних признаках, составляя так называемую внешнюю характерность. К внешней характерности роли можно отнести все особенности речи (картавость, шепелявость), все особенности физических качеств человека (хромота, близорукость, резко выраженная жестикуляция или иная физическая привычка). Прежде всего, надо узнать причину той или иной внешней характерности. Уже одно это даст внутреннее, логическое, а внешне механическое обоснование ее.

План работы:

1. Тема произведения, ее актуальность для зрителя; необходимость целеустремленного раскрытия темы. Исторические условия эпохи создания произведения. Знакомство с материалами, раскрывающими показанную в пьесе действительность: историческими, научными, литературными, публицистическими, мемуарными, иконографическими;

2. Идея драматического произведения, его сверхзадача; мировоззрение драматурга;

3. Основной драматический конфликт и отношения действующих лиц в этом конфликте, сквозное действие и расстановка персонажей пьесы по отношению к нему (развитие действия и контрдействия); 
4. События пьесы, как этапы непрерывно развивающегося сквозного действия; Событийный ряд:

Ведущее предлагаемое обстоятельство - точка отсчета сюжета «С чего все началось?» Здесь кроется зерно определения будущего спектакля. Верно найденное «ведущее предлагаемое обстоятельство» проясняет атмосферу пьесы и вскрывает природу конфликта, оно - надежный ориентир, конкретизирующий весь замысел спектакля.

Исходное (начальное) событие - является конфликтным источником. Это своеобразный эмоциональный зачин спектакля, его камертон, оно может начинаться за пределами спектакля. Оно фокусирует, отражает в себе (как капля воды - океан) исходное предлагаемое обстоятельство, зарождаясь в его недрах.

Основное событие - интрига. Здесь начинается борьба по сквозному действию, вступает в силу ведущее предлагаемое обстоятельство пьесы.

Центральное событие - коренной поворот, переломный момент. Центральное событие - это в спектакле высший пик борьбы по сквозному действию. От центрального события действие стремиться к «развязке», к тому, что называется «главным событием». Этот центральный узел, пожалуй, самое сложное звено сюжета. Его определение неразрывно связано с режиссерским замыслом, с ответом на вопрос «про что?», а потому и оставляет массу возможностей для индивидуального прочтения.

В финальном событии - кончается борьба по сквозному действию, исчерпывается ведущее предлагаемое обстоятельство

Главное событие - самое последнее событие спектакля, заключающее 'зерно' сверхзадачи; в нем как бы 'просветляется' идея произведения; здесь решается судьба исходного предлагаемого обстоятельства - мы узнаем, что стало с ним, изменилось ли оно или осталось прежним.

5. Выявление характеров действующих лиц на гребне событийного ряда.

6. Определение сквозного действия каждой роли, ее образное «зерно»; перспектива артиста и перспектива роли.

7. Атмосфера, в которой живут и действуют персонажи.

8. Структура пьесы и ее композиционные особенности.

9. Стилевая и жанровая характеристика пьесы.

Сверхзадача и сквозное действие. Понятия «сквозное действие» и «сверхзадача» - одни из самых важных аспектов эстетических принципов Станиславского (см.: Скляр, 2003). Станиславский в своих трудах раскрывает суть различных элементов сценического творчества, изучение которых необходимо для наиболее ясного понимания метода действенного анализа пьесы и роли. Но понятия «сквозное действие» и «сверхзадача» являются наиболее часто употребляемыми. Сам Станиславский о сверхзадаче и 
сквозном действии в своей книге «Работа актера над собой», в которой он дает подробнейшее описание понятий, объясняет их практическую необходимость и значение в режиссуре, актерском мастерстве, писал следующее: «Сверхзадача и сквозное действие - главная жизненная суть, артерия, нерв, пульс пьесы. Сверхзадача (хотение), сквозное действие (стремление) и выполнение его (действие) создают творческий процесс переживания» (Станиславский, 1954: 360).

Станиславский говорил, что подобно тому, как из зерна вырастает растение, так точно из отдельной мысли и чувства писателя вырастает его произведение. Мысли, чувства, мечты писателя, наполняющие его жизнь, волнующие его сердце, толкают его на путь творчества. Они становятся основой пьесы, ради них писатель пишет свое литературное произведение. Весь его жизненный опыт, радости и горести, перенесенные им самим, становятся основой драматургического произведения, ради них он берется за перо. Главной задачей актеров и режиссеров является, с точки зрения Станиславского, умение передать на сцене те мысли и чувства писателя, во имя которых он написал пьесу.

Константин Сергеевич пишет: «Условимся же на будущее время называть эту основную, главную, всеобъемлющую цель, притягивающую к себе все без исключения задачи, вызывающую творческое стремление двигателей психической жизни и элементов самочувствия артисто-роли, сверхзадачей произведения писателя»; «Без субъективных переживаний творящего она (сверхзадача) суха, мертва. Необходимо искать откликов в душе артиста, для того чтобы и сверхзадача, и роль сделались живыми, трепещущими, сияющими всеми красками подлинной человеческой жизни» (там же).

Таким образом, определение сверхзадачи - это глубокое проникновение в духовный мир писателя, в его замысел, в те побудительные причины, которые двигали пером автора.

Сверхзадача, по Станиславскому, должна быть «сознательной», идущей от ума, от творческой мысли актера, эмоциональной, возбуждающей всю его человеческую природу и, наконец, волевой, идущей от его «душевного и физического существа». Сверхзадача должна пробудить творческое воображение артиста, возбудить веру, возбудить всю его психическую жизнь.

Причем у сверхзадачи есть особенность - одна и та же верно определенная сверхзадача, обязательная для всех исполнителей, пробудит у каждого исполнителя свое отношение, свои индивидуальные отклики в душе. Очень важно при поисках сверхзадачи наличие ее точного определения, меткости в ее наименовании, выражения ее наиболее действенными словами, так как часто неправильное обозначение сверхзадачи может повести исполнителей по ложному пути. В труде Станиславского достаточно много примеров подобных «ложных» ситуаций. 
Необходимо, чтобы определение сверхзадачи давало смысл и направление работе, чтобы сверхзадача бралась из самой гущи пьесы, из самых глубоких ее тайников. Сверхзадача толкнула автора на создание своего произведения - она же и должна направить творчество исполнителей. Фундаментальным понятием метода является сверхзадача - то есть идея произведения, обращенная в сегодняшнее время, то, во имя чего ставится сегодня спектакль. Постижению сверхзадачи помогает проникновение в сверх-сверхзадачу автора, в его мировоззрение.

Путь воплощения сверхзадачи - сквозное действие - это та реальная, конкретная борьба, происходящая на глазах зрителей, в результате которой утверждается сверхзадача. Для артиста сквозное действие является прямым продолжением линий стремления двигателей психической жизни, берущих свое начало от ума, воли и чувства творящего артиста. Не будь сквозного действия, все куски и задачи пьесы, все предлагаемые обстоятельства, общение, приспособления, моменты правды и веры и прочее прозябали бы порознь друг от друга, без всякой надежды ожить.

Выявляя конфликт пьесы, мы сталкиваемся с необходимостью определения сквозного действия и контрдействия. Сквозное действие - путь борьбы, направленный на достижение сверхзадачи, на приближение к ней. В определении сквозного действия всегда присутствует борьба, а, следовательно, должна быть и вторая сторона - то, с чем необходимо бороться, т. е. контрдействие, та сила, которая сопротивляется решению поставленной проблемы. Таким образом, сквозное действие и контрдействие - составляющие силы сценического конфликта. Линия контрдействия складывается из отдельных моментов, из маленьких линий жизни артисто-роли.

\section{СПИСОК ЛИТЕРАТУРЫ}

Бейлис, В. Иванов, В. (2009) Диалоги и монологи. Профессия: режиссер. М. : Лазурь. 272 с.

Скляр, И. Г. (2003) Эстетика сценического творчества актера (на материалах системы К. С. Станиславского) : дисс.... канд. филос. н. М. 133 с.

Станиславский, К. С. (1954) Собрание сочинений : в 8 т. М. : Искусство. T. II: Работа актера над собой. Ч. I. Работа над собой в творческом процессе переживания. 424 с.

Юркин Вячеслав Александрович - профессор кафедры культуры и искусства Московского гуманитарного университета, заслуженный работник культуры РФ. Адрес: 111395, Россия, г. Москва, ул. Юности, д. 5. Тел.: +7 (499) 374-59-40. Эл. адрес: 3730014@mail.ru 
Yurkin Viacheslav Aleksandrovich, Professor, Department of Culture and Art, Moscow University for the Humanities, Honored Worker of Culture of the Russian Federation. Postal address: 5 Yunosti St., Moscow, Russian Federation 111395. Tel.+7 (499) 374-59-40. E-mail: 3730014@mail.ru 